\title{
Endocrine system on chip for a diabetes treatment model
}

Dao Thi Thuy Nguyen, Danny van Noort, In-Kyung Jeong and Sungsu Park

Journal Article

\section{Tweet}

N.B.: When citing this work, cite the original article.

Original Publication:

Dao Thi Thuy Nguyen, Danny van Noort, In-Kyung Jeong and Sungsu Park, Endocrine system on chip for a diabetes treatment model, Biofabrication, 2017. 9(1)

http://dx.doi.org/10.1088/1758-5090/aa5cc9

Copyright: IOP Publishing: Hybrid Open Access

http://www.iop.org/

Postprint available at: Linköping University Electronic Press

http://urn.kb.se/resolve?urn=urn:nbn:se:liu:diva-136651

LINKÖPINGS

UNIVERSITET 


\title{
Endocrine system on chip for a diabetes treatment model
}

\author{
Dao Thi Thuy Nguyen ${ }_{2}^{a} \dagger$ Danny van Noort, ${ }^{\text {b }}+$ In-Kyung Jeong ${ }^{c}$ and Sungsu Park ${ }^{\mathrm{d}^{*}}$
}

\author{
a.Department of Chemistry and Nano Sciences, Ewha Womans University, Seoul 03760, Korea. \\ b. Biotechnology, IFM, Linköping University, Linköping 58183, Sweden. \\ c. Department of Endocrinology, Kyung Hee University Hospital at Gangdong, Kyung Hee University College of Medicine, \\ Seoul 05278, Korea. \\ ${ }^{d}$ School of Mechanical Engineering, Sungkyunkwan University, Suwon 16419, Korea. \\ †These authors contributed equally to this work. *Correspondence: email [nanopark@skku.edu]
}

The endocrine system is a collection of glands producing hormones which, among others, regulates metabolism, growth and development. One important group of endocrine diseases is diabetes, which is caused by a deficiency or diminished effectiveness of endogenous insulin. By using a microfluidic perfused 3D cell-culture chip, we developed an 'endocrine system on chip' to potentially be able to screen drugs for the treatment of diabetes by measuring insulin release over time. Insulin-secreting $\beta$-cells are located in the pancreas, while L-cells, located in the small intestines, stimulate insulin secretion. Thus, we constructed a co-culture of intestinal-pancreatic cells to measure the effect of glucose on the production of glucagon-like peptide-1 (GLP-1) from the L-cell line (GLUTag) and insulin from the pancreatic $\beta$-cell line (INS-1). After three days of culture, both cell lines formed aggregates, exhibited 3D cell morphology, and showed good viability (>95\%). We separately measured the dynamic profile of GLP-1 and insulin release at glucose concentrations of 0.5 and $20 \mathrm{mM}$, as well as the combined effect of GLP-1 on insulin production at these glucose concentrations. In response to glucose stimuli, GLUTag and INS-1 cells produced higher amounts of GLP-1 and insulin, respectively, compared to a static 2D cell culture. INS-1 combined with GLUTag cells exhibited an even higher insulin production in response to glucose stimulation. At higher glucose concentrations, the diabetes model on chip showed faster saturation of the insulin level. Our results suggest that the endocrine system developed in this study is a useful tool for observing dynamical changes in endocrine hormones (GLP-1 and insulin) in a glucose-dependent environment. Moreover, it can potentially be used to screen GLP-1 analogues and natural insulin and GLP-1 stimulants for diabetes treatment.

\section{Introduction}

Diabetes mellitus (DM) is a group of diverse metabolic diseases caused by the deficiency or diminished effectiveness of endogenous insulin, which results in high blood glucose levels (hyperglycaemia) ${ }^{1}$. There are two major types of DM: Type 1 and Type 2. Type 1 DM (T1DM) is the result of the destruction of pancreatic $\beta$-cells²; Type 2 DM (T2DM) is the result of insulin resistance or insulin insensitivity in tissues such as fat, liver and skeletal muscle tissue ${ }^{3,4}$. T2DM accounts for about $90 \%$ of all cases of diabetes. 
Endocrine hormones are released from a large number of different cell types, regulating the glucose level in blood. Here, we will focus on those cells from the intestine and pancreas which play a leading role in insulin regulation, namely, L-cells and $\beta$-cells, respectively. The pancreas, which has exocrine-endocrine functions, consists of four different components: exocrine tissue (98\%), ducts, endocrine cells (1-2\%), and connective tissue ${ }^{5}$. $\beta$-cells are located in the islets of Langerhans which are embedded in the endocrine component of the pancreas and consist of five functionally different cell types. Of these, $\alpha$-cells (15-20\%), which secrete glucagon with a hyperglycaemic action and $\beta$-cells (65-80\%), which produce insulin for regulating the glucose levels in the blood, are the most represented ${ }^{6}$. Insulin secretion is mainly induced via a glucosestimulated pathway. The glucose-stimulated insulin secretion in the islets is coupled to the metabolic state of the $\beta$-cells and involves both glycolytic and Krebs cycle metabolism? Hyperglycaemia can cause problems for nerves, kidneys, eyes, arteries and heart ${ }^{8}$. Increasing insulin secretion as well as decreasing insulin resistance is the primary objective in the treatment of T2DM9 ${ }^{9}$.

The incretin glucagon-like peptide-1 (GLP-1), a small peptide hormone that stimulates insulin secretion in a glucose-dependent manner ${ }^{10,11}$, enhances insulin release and thus plays an important role in the regulation of glucose homeostasis. GLP-1 is produced in response to hormonal, neutral, and nutrient stimuli by enteroendocrine L-cells which are located in the distal ileum (the final section of the small intestines) and colon. Because GLP-1 induces insulin production, it has been considered as a treatment to increase insulin production. However, native GLP-1 has a half-life of less than 2 min because of its rapid degradation by dipeptidyl peptidase-4 (DPP-4) present in the blood. This complicates the application of GLP-1 as an anti-diabetic drug to restore glucose competence in the islets of Langerhans and $\beta$-cell regeneration. Stable analogues of GLP-1, such as exendin-4 and liraglutide, as well as DPP-4 inhibitors such as sitaglitin, are available as treatments for T2DM ${ }^{12}$. Enhancing endogenous GLP-1 secretion is a novel and more physiological option in incretin-based diabetes therapy.

To establish a highly functioning endocrine system on chip, we have adapted the 3D microfluidic cell culture chip (3D- $\mu \mathrm{FCC}$ ) developed by Toh et al. ${ }^{13}$. Microfluidic devices have the potential to control the cell culture environment, mimicking the in vivo 3D morphology and functions in vitro. Furthermore, microfluidics not only allows for the easy control and manipulation of small liquid volumes, which are in physiological scales, but also the generation of mechanical forces by the fluid flow, thereby mimicking the in vivo microenvironment of cells ${ }^{14,15}$. Thus, a microfluidic device helps maintain cell functions and can be used for predictive drug screening on in vitro screening models ${ }^{16,17}$. Recent innovations in microfluidic technologies include the so called 'organ-on-a-chip' that was thrust in the limelight with the publication of lung-on-a-chip ${ }^{14,18}$, with later devices mimicking the liver, kidney, heart, gut, breast and blood vessels as well 19,20 .

Until now, research involving endocrine microfluidic systems has focused on culturing islets of Langerhans to measure their functions before transplantation ${ }^{21}$; the deterioration of the islet 
endothelium cell morphology due to sheer stress and media composition ${ }^{22}$; insulin production under defined temporal glucose gradients ${ }^{23}$; a real-time insulin detection system based on a rapid electrophoresis-based immunoassay ${ }^{24,25}$; and a method for monitoring the functionality of the islets in microfluidics by measuring zinc secretion ${ }^{26}$, as $\mathrm{Zn}^{2+}$ is co-secreted with insulin from the $\beta$-cells ${ }^{27}$.

Our chip for the endocrine system was constructed by connecting two $3 \mathrm{D}-\mu \mathrm{FCC}$ chips ${ }^{13}$ : one with L-cells and the other with $\beta$-cells. The system was used to study insulin secretion from pancreatic $\beta$-cells (INS-1) and GLP-1 secretion from intestinal L-cells (GLUTag) as a function of glucose concentrations and flow rates. We showed that changing the glucose concentration in the media changes the GLP- 1 release by the L-cells and therefore the insulin release by the $\beta$-cells. Glucose increases the release of insulin while GLP-1 increases the production of insulin in the $\beta$ cells ${ }^{28}$. This was evident from the differences between the insulin quantity measured at the output of the $\beta$-cell 3D- $\mu$ FCC chip when it is exposed to high glucose/GLP-1 media and to high glucose media, respectively. The results of GLP-1 and insulin secretion were measured by enzyme-linked immunosorbent assay (ELISA). Thus, the interaction between GLP-1 and insulin and its effect on insulin production can be monitored using the endocrine system on chip.
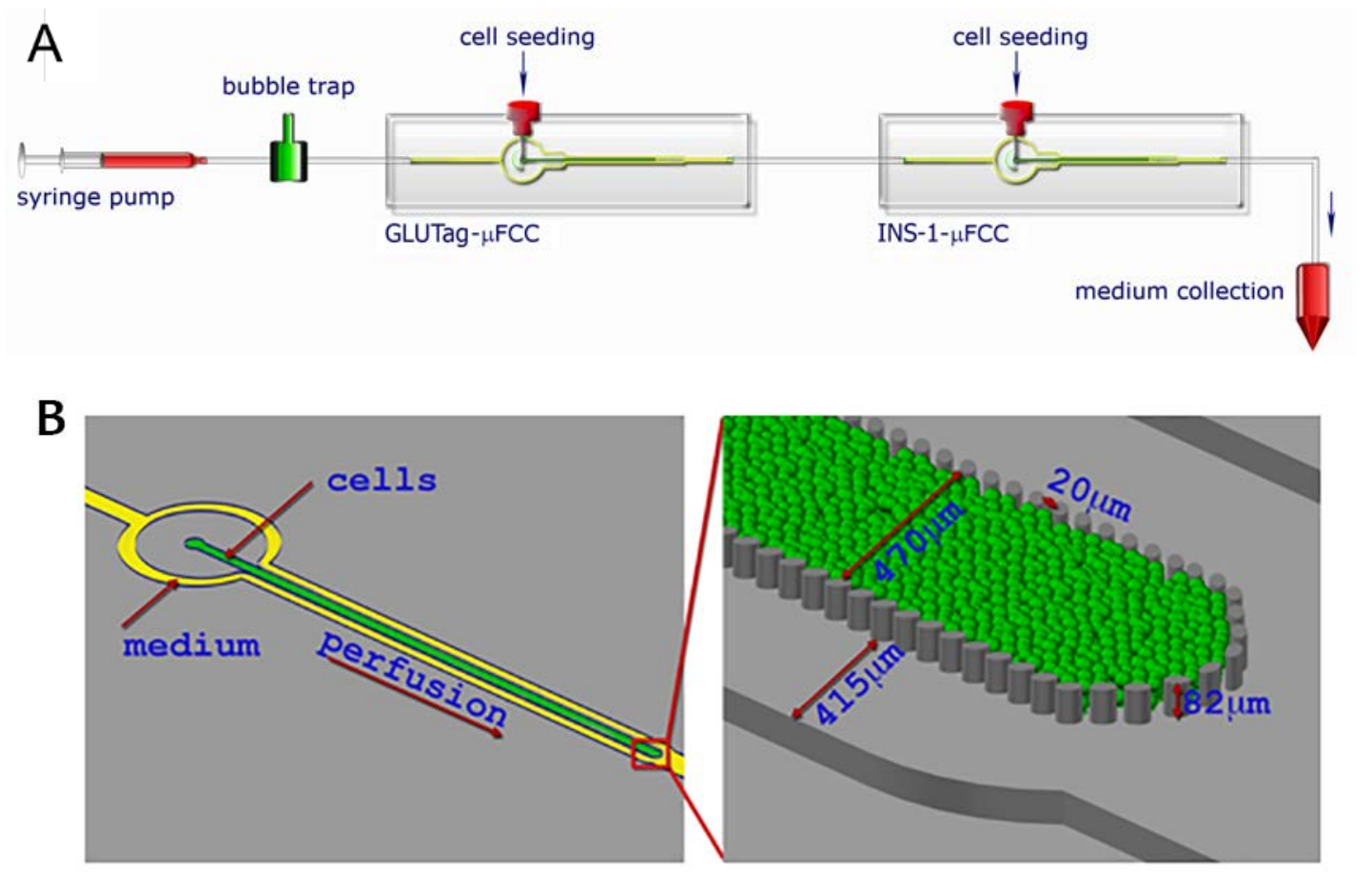

Figure 1. Schematic of the endocrine system on chip. (A) Setup for the chip. By using a syringe pump and withdrawing flow, the cells are loaded into their respective chambers (flow rate: $1 \mu \mathrm{l} / \mathrm{min}$ ); 'medium in' is the input culture media by perfusion (flow rate: $0.5 \mu \mathrm{l} / \mathrm{min}$ ) and supply glucose by perfusion (flow rate: 2 and $10 \mu \mathrm{l} / \mathrm{min}$ ); at 'medium out', the perfusate is collected for further analysis. The two cell chambers are connected by a 'connection tube'. (B) Dimensions of 3D microfluidic chip. Micropillars divided the microfluidic channel into a central cell culture compartment and two side channels for perfusion of the culture medium. 


\section{Experimental details}

\subsection{Fabrication of microfluidic device}

The epoxy-based photoresist SU-8 (MicroChem Corp., USA) was used to create the master for the pillar array and channels ${ }^{13}$. In detail, a 4-inch silicon wafer was cleaned with acetone and isopropyl alcohol and then dried in N2. SU8-2035 was spin-coated on the wafer for $30 \mathrm{sec}$ at 1700 rpm for the first layer and SU8-2007 was spin-coated on the wafer at $1000 \mathrm{rpm}$ for the second layer to get thicknesses of $70 \mu \mathrm{m}$ and $12 \mu \mathrm{m}$, respectively, resulting in an 82- $\mu \mathrm{m}$-thick layer. The coated wafer was then exposed to UV light through a film mask and was then developed. Soft lithography was used to transfer the patterns on the master into a polydimethyl siloxane (PDMS) (Sylgard 184, Corning, USA) layer ${ }^{13}$. PDMS was first degassed in vacuum and then poured into the wafer and cured at $80^{\circ} \mathrm{C}$ for $2 \mathrm{~h}$. The PDMS layer was then peeled off the master and holes were punched (Syneo Co., USA) for inlets and outlets. The PDMS layer was then plasma-treated and thereafter bonded to a glass microscope slide. The inlets and outlets were connected to Tygon tubing (AAD04103; Saint-Gobain PPL Corp.) via small metal tubes (New England Small Tube Co., USA). Figure 1A shows the experimental setup of endocrine system on chip, while Fig. 1B shows the microfluidic chip. Elliptical micropillars $(30 \times 50 \mu \mathrm{m})$ divide the microfluidic channel into a $470-\mu \mathrm{m}$-wide central cell culture compartment and two $415-\mu \mathrm{m}$-wide side channels for the perfusion of culture mediums. The gaps between the pillars are $20 \mu \mathrm{m}$ wide.

\subsection{Cell lines}

Instead of culturing the islets of Langerhans on chip, we chose to use the $\beta$-cell line INS-128 from a rat because it produces insulin and can be readily obtained and cultured. The islets of Langerhans must be freshly isolated from animals before experiments, making it a tedious and difficult procedure ${ }^{30}$ and going against the idea of reducing the use of animals. Unfortunately, human-insulin-secreting cell lines are notoriously difficult to establish and have only recently been achieved at Université Pierre et Marie Curie-Paris ${ }^{31}$.

For the GLP-1-producing L-cells, we used the GLUTag cell line ${ }^{32}$. GLUTag cells constitute a stable, immortalized and relatively differentiated murine enteroendocrine cell line that expresses the proglucagon gene and secretes glucagon-like peptides in a regulated manner. GLUTag cells are used as GLP-1/GLP-2 secretagogues and in studies on enteroendocrine glucagon gene transcription.

Pancreatic $\beta$-cells (INS-1 cells) were cultured in RPMI (11.1 mmol/l glucose, GIBCO-11875) plus 10\% FBS (GIBCO-16000), 1\% penicillin/streptomycin (GIBCO-15240), $10 \mathrm{mM}$ HEPES (Hyclone-SH30237), $1 \mathrm{mM}$ sodium pyruvate (GIBCO-11360), and $50 \mu \mathrm{M}$ 2-mercaptoethanol (GIBCO-21985-023). Intestinal L-cells (GLUTag cells) were cultured in DMEM (5.5 mmol/l glucose, Welgene) plus 10\% FBS (Welgene) and 1\% penicillin/streptomycin (GIBCO-15240).

\subsection{Cell loading and culture on chip}


The medium used for the perfusion of cells cultured on the chip was low-glucose DMEM (5.5 mM glucose) + HEPES (20:1). The medium also contained 60 mM HEPES buffer to maintain the $\mathrm{pH}$ under atmospheric environment. The cells were loaded into the cell reservoir after which they were delivered to the central cell culture compartment via the outlet by withdrawing the flow at a flow rate $1-2 \mu \mathrm{l} / \mathrm{min}$, while blocking the media inlet. Withdrawal of the cell suspension is considered to be less harmful to the cells, compared with injecting the cells directly into the channel. The cells loaded on the perfusion chip were cultured on a hot plate maintained at $37^{\circ} \mathrm{C}$. The flow rate during the culture was $0.5 \mu \mathrm{l} / \mathrm{min}$; the cell reservoir was blocked with a metal pin while the medium was supplied via the inlet by using a syringe pump for perfusion.

\subsection{Live/dead cell staining}

Cell viability was assessed by live/dead cell staining at 1,2, and 3 days after the cell culture on the chips. Ethidium homodimer-1 and calcein-AM were diluted (4:1 in ratio) in the culture medium and infused into the microfluidic chips at a flow rate of $10 \mu \mathrm{l} / \mathrm{min}$ for $30 \mathrm{~min}$. Images were taken by confocal laser scanning microscopy (CLSM) (LSM510 Meta, Carl Zeiss, Germany). The viability was quantified using the image analysis software ImageJ, by analysing the percentage of live cells stained with calcein AM (green) and dead cells stained with EthD-1 (red).

\subsection{F-actin staining}

F-actin distribution was investigated after 3 days of the cell culture. F-actin in the cells was stained in situ by infusing all solutions used for staining in the chips at a flow rate of $10 \mu \mathrm{l} / \mathrm{min}$ by using a syringe pump. The cells were fixed with 3.7\% paraformaldehyde for $30 \mathrm{~min}$ and permeabilized with $0.2 \%$ Triton X-100 for $20 \mathrm{~min}$. Then, they were stained with 1:200 phalloidin conjugated with rhodamine in PBS for 30 min. Finally, the cells were washed with PBS for 10 min and observed by CLSM (LSM510 Meta, Carl Zeiss, Germany).

\subsection{SEM imaging}

The chips for scanning electron microscopy (SEM) imaging were prepared by reversible bonding the microfluidic channel onto a thin PDMS layer instead of a cover glass. After 3 days of the perfusion culture, $3.7 \%$ paraformaldehyde was infused for $30 \mathrm{~min}$, followed by $1 \%$ osmium tetroxide for $1 \mathrm{~h}$. Then, the PDMS device was peeled off and the exposed microfluidic channel with the cells were sequentially dehydrated with ethanol $(50,70,75,80,85,90,95$, 99, and $100 \%$ ). Finally, the sample was coated with a 5 -nm-thick platinum layer by using a sputterer (20 $\mathrm{mA}, 60 \mathrm{~s}$ ) and observed by field-emission scanning electron microscopy (JEM-2100F, JEOL, Japan).

\subsection{Insulin and GLP-1 secretion}

About $10^{5}$ INS- 1 cells and $2 \times 10^{5}$ GLUTag cells were loaded per chip. The chip was placed in distilled water at $37^{\circ} \mathrm{C}$ and perfusion cultured at a flow rate $0.5 \mu \mathrm{l} / \mathrm{min}$. For taking measurements at different glucose levels, after 1 day of culture, the cells were washed with a glucose-free KREB buffer for $2 \mathrm{~h}$ at a flow rate of $1 \mu \mathrm{l} / \mathrm{min}$. The glucose-free KREB buffer contained $140 \mathrm{mMNaCl}, 3.6$ 
mMKCl, $0.5 \mathrm{mM} \mathrm{NaH}_{2} \mathrm{PO}_{4}, 2 \mathrm{mM} \mathrm{NaHCO}$, $1.5 \mathrm{mM} \mathrm{CaCl}_{2}, 0.5 \mathrm{mM} \mathrm{MgSO}$, $10 \mathrm{mM}$ HEPES, and $0.1 \%$ BSA.

\subsection{One-chamber chip}

Insulin and GLP-1 secretion were measured for $2 \mathrm{~h}$ at two different flow rates (2 and $10 \mu \mathrm{l} / \mathrm{min}$ ) and glucose levels $\left(0.5\right.$ and $20 \mathrm{mM}$ ). The cell cultures were maintained at $37^{\circ} \mathrm{C}$ and $5 \% \mathrm{CO}_{2}$ during washing and incubation. D-glucose was prepared at $1 \mathrm{M}$ stock and mixed with other reagents in distilled water to get the final concentration of 0.5 and $20 \mathrm{mM}$. Other reagents (such as GLP-1) were prepared in stock $(1 \mathrm{mg} / \mathrm{ml})$ and dissolved in a D-glucose/KREB buffer to get the experimental concentration. The $\mathrm{pH}$ values of buffers were adjusted to 7.4 by using $\mathrm{NaOH}$ or $\mathrm{HCl}$. Samples of the supernatant were collected at the outlet of the chip every 15 min and then centrifuged to remove cells which were then stored in a freezer $\left(-20^{\circ} \mathrm{C}\right)$ until quantification with an ELISA kit.

\subsection{Two-chamber chip}

A co-culture was obtained by culturing GLUTag and INS-1 cells in two separate chambers on the chip, while connecting the outlet of the GLUTag chamber to the inlet of the INS-1 chamber by external tubing (Fig. 1A). The effect of GLP-1 on insulin secretion was observed at two different concentrations of D-glucose $(0.5$ and $20 \mathrm{mM})$ and at a flow rate of $10 \mu \mathrm{l} / \mathrm{min}$. Further, samples were collected every 15 min to measure the dynamic change in insulin secretion.

\subsection{Insulin and GLP-1 detection}

The insulin level was measured using an ELISA kit for rat insulin (rat ultrasensitive insulin ELISA, 80-INSRTU-E01, ALPCO, USA). GLP-1 was assayed using an ELISA kit for GLP-1 (7-36 and 9-36) (GLP-1 total ELISA kit, EZGLP1T-36K, Millipore). Further, the glucose concentration in the media and buffers was measured using an AmplexRed glucose kit (A22189, Life Technologies). These methods were conducted according to the protocols provided by the manufacturers.

\section{Results and discussion}

\subsection{D microfluidic perfusion cell culture of INS-1 and GLUTag}

We established a 3D culture method for two different cell types, INS-1 and GLUTag, in a microfluidic perfusion chip. Toh et al. ${ }^{13}$ showed that cells cultured in a microfluidic system can maintain their cell shape, morphology and functions for up to $72 \mathrm{~h}$ in a 3D microfluidic system, while also showing an increased sensitivity of the in vitro 3D cell culture towards drugs ${ }^{17}$. Figures 2A and 2D show the cell viability (>95\%) for both the INS-1 and GLUTag cells after $72 \mathrm{~h}$ of perfusion culture. At this time, the cells formed tight structures and secreted extra cellular matrix (ECM). The cells were stained with calcein AM (which stains live cells green) and ethidium homodimer-1 (which stains dead cells red). 
Confocal images of F-actin staining showed that both cells types cultured in the microfluidic device maintained a 3D configuration (Fig. 2B and 2E), unlike the cells cultured in petri dishes that flattened and formed 2D configurations (Fig. 2B and 2E insets). Furthermore, SEM showed that the cells had rounded 3D cell morphology and formed cell-cell linkages (Fig. 2C and 2F). These results indicate that the cells maintained the 3D morphology after 3 days of perfusion culture, which contributed to their enhanced viability and functionality.
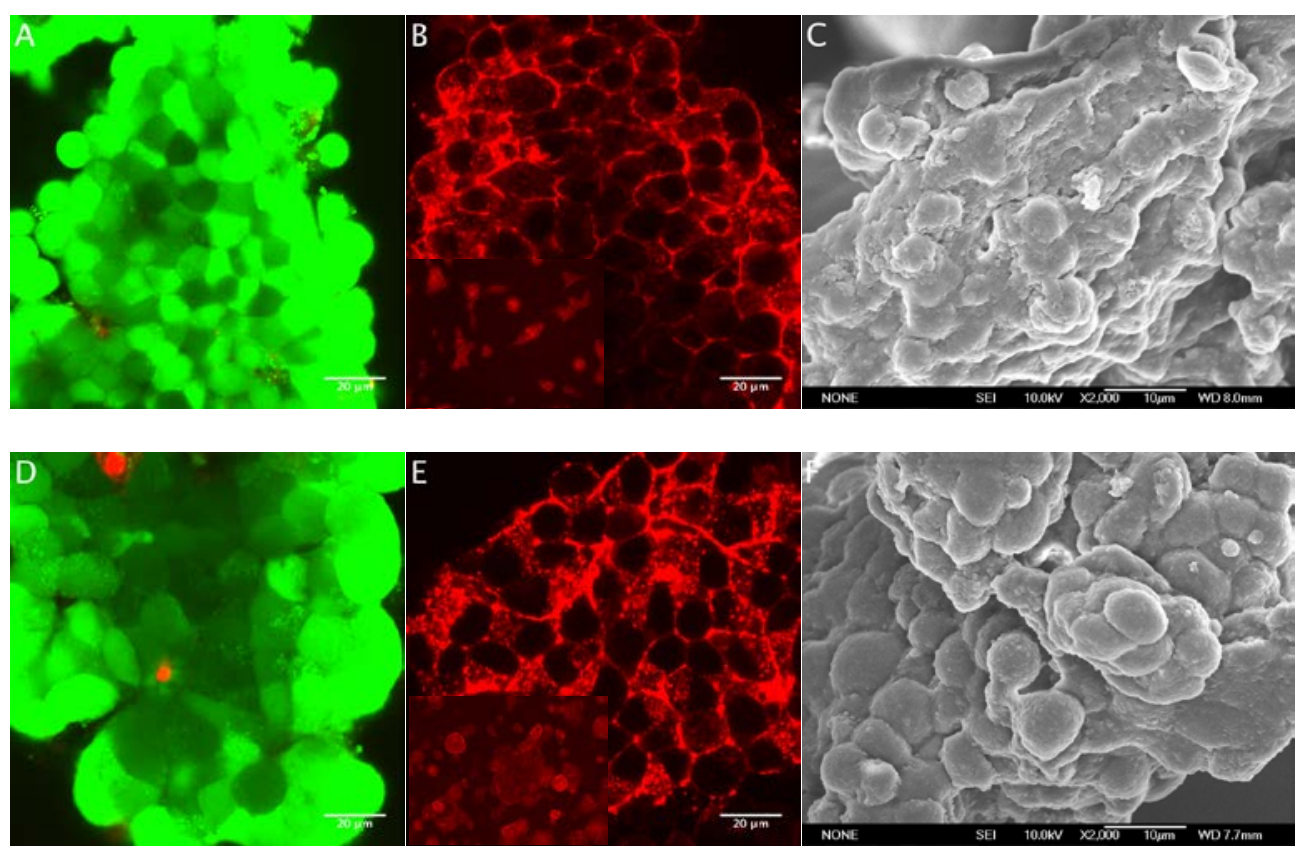

Figure 2. Cell viability and morphology of INS-1 an GLUTag cells co-cultured in 3D-culture microfluidic device at Day 3. (A), (D) Live/dead staining of INS-1 and GLUTag cell lines (Green: Ethidium homodimer-1; Red: Calcein-AM). (B), (E) F-actin staining of INS-1 and GLUTag in perfusion 3D culture, in comparison to F-actin in 2D monolayer cultures (inserts). (C), (F) SEM micrograph of INS-1 and GLUTag.

\subsection{Insulin secretion in culture dishes and 3D- $\mu$ FCCs}

Glucose metabolism and its relation with glucose-stimulated insulin secretion were studied in both the 2D cell culture and microfluidics-based 3D INS-1 cell culture and co-culture with GLUTag platforms. Before every measurement the cells were exposed to glucose-free KREB buffer. Figure 3 compares the production of insulin in culture wells (2D monolayer) containing $20 \mathrm{mM}$ glucose and insulin in the microfluidic channels (3D microfluidic device) and culture wells (2D monolayer) in a $20 \mathrm{mM}$ glucose solution at a flow rate of $10 \mu \mathrm{l} / \mathrm{min}$. After $2 \mathrm{~h}$, insulin production was significantly higher in microfluidics than that in a plated culture; this was probably caused by the rapid loss of differentiated functions in the 2D cultures ${ }^{33}$. Previous studies have shown that cell-specific functions (in this case, insulin secretion) are maintained in 3D microfluidic systems ${ }^{34}$. Another consideration for higher insulin production in a microfluidics-based system is because of the perfusion, which means there was a continuous supply of nutrients and removal of waste products. In a 2D culture, this is not the case. Thus, after 
$2 \mathrm{~h}$, the insulin secretion in the 3D culture was up to 1.6 times higher for the INS-1 chip and 1.8 times higher for the co-culture compared to the 2D culture.

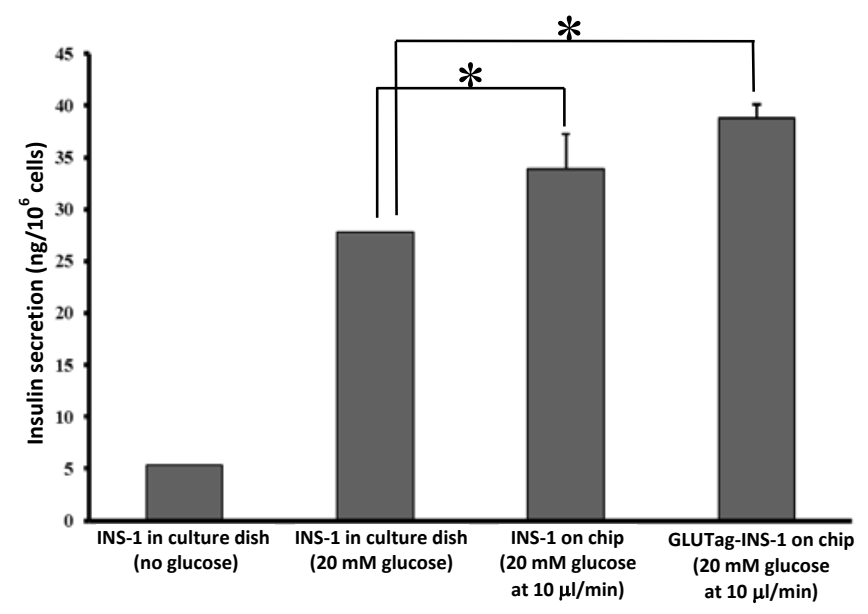

Figure 3. Comparison of insulin production from 2D cell culture of INS-1, INS-1 on chip and GLUTag and INS-1 on chip in the presence of $20 \mathrm{mM}$ glucose. Data are presented as means \pm SD of three culture dishes (2D culture) and three chips (3D- $\mu$ FCC) for INS-1 cells and INS-1 connected GLUTag cells. * indicates statistical significance compared to 2D culture (using student t-test, $\mathrm{P}<0.05$ ).

\subsection{Effect of flow rate on insulin and GLP-1 secretion}

To understand the effect of flow rate on the insulin and GLP-1 production, we performed the measurements at two different flow rates of 2 and $10 \mu \mathrm{l} / \mathrm{min}$. Moreover, the effect of the flow rate was compared at two different glucose concentrations in the perfused medium. Before the measurements, the cells were washed with glucose-free KREB buffer for $2 \mathrm{~h}$. A higher flow rate resulted in more glucose being taken up by the cells, resulting in higher secretion levels (Fig. 4). At $0.5 \mathrm{mM}$ glucose concentration and $10 \mu \mathrm{l} / \mathrm{min}$ perfusion flow rate, the accumulated insulin secretion after $2 \mathrm{~h}$ was 5.7 times that at $2 \mu \mathrm{l} / \mathrm{min}$ flow rate (Fig. 4A). At $20 \mathrm{mM}$ glucose concentration and $10 \mu \mathrm{l} / \mathrm{min}$ perfusion flow rate, the insulin secretion was 7.9 times that at 2 $\mu \mathrm{l} / \mathrm{min}$ flow rate (Fig 4A). Similar results were observed for GLP-1 production of the GLUtag cells (Fig. 4B). At $0.5 \mathrm{mM}$ glucose concentration and $10 \mu \mathrm{l} / \mathrm{min}$ perfusion flow rate, the accumulated GLP-1 secretion after $2 \mathrm{~h}$ was 1.7 times that at $2 \mu \mathrm{l} / \mathrm{min}$ flow rate (Fig 4A), while at $20 \mathrm{mM}$ glucose concentration and $10 \mu \mathrm{l} / \mathrm{min}$ perfusion flow rate, it was 8.4 times that at $2 \mu \mathrm{l} / \mathrm{min}$ flow rate. Thus, a change in the flow rate affected the glucose uptake and therefore resulted in a change in the insulin and GLP-1 secretion. However, it should be noted that increasing the flow rate even further would result in lower secretion owing to the effect of sheer stress on the cells. For the following experiments, we measured cell secretion at a flow rate of $10 \mu \mathrm{l} / \mathrm{min}$. 
A

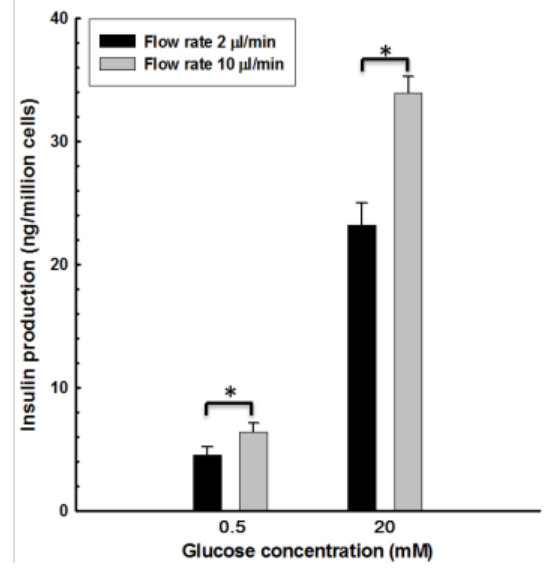

B

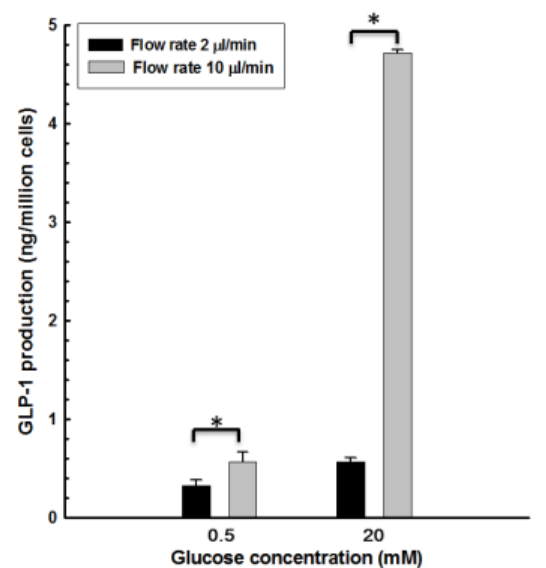

Figure 4. Change in insulin and GLP-1 production in the chip depends on flow rate and glucose concentration. (A) Insulin production after $2 \mathrm{~h}: 2 \mu \mathrm{l} / \mathrm{min}$ (grey column) and $10 \mu \mathrm{l} / \mathrm{min}$ (black column); the column represents numerical means. $\mathrm{n}=3$ replications. Error bars represent standard deviation, and asterisk $\left(^{*}\right)$ denotes significance $(\mathrm{P}<0.05)$ obtained using t-test: two-sample assuming unequal variances. (B) GLP-1 production after $2 \mathrm{~h}: 2 \mu \mathrm{l} / \mathrm{min}$ (grey column) and $10 \mu \mathrm{l} / \mathrm{min}$ (black column); the column represents numerical means, $\mathrm{n}=3$ replications. Error bars represent standard deviation, and asterisk $\left({ }^{*}\right)$ denotes significance $(\mathrm{P}<0.05)$ obtained using t-test: two-sample assuming unequal variances.

\subsection{Effect of glucose concentration on insulin and GLP-1 secretion}

It is assumed that higher glucose levels in the blood will cause higher insulin secretion. This is true for the total insulin amount secreted. However, the following results show that a higher glucose level results in faster saturation of insulin secretion. Figure $5 \mathrm{~A}$ shows that the insulin saturation point of about $4.2 \mathrm{ng} /$ million cells was reached within $30 \mathrm{~min}$ at $20 \mathrm{mM}$ glucose concentration, while at $0.5 \mathrm{mM}$ glucose concentration, this secretion level was only reached after $120 \mathrm{~min}$. However, the accumulative amount of insulin secreted at $20 \mathrm{mM}$ glucose concentration was 1.5 times higher than that at $0.5 \mathrm{mM}$ glucose concentration. Thus, we proved that for the microfluidic device, the amount of insulin secretion directly depends on the glucose concentration.

From the above results, it is clear that the microfluidic perfusion device successfully resulted in insulin secretion from the functional $\beta$-cells. This demonstrates the key role of dynamics in glucose-stimulated insulin secretion. A higher influx of glucose will need more insulin to be released faster to control the blood glucose level more effectively. 

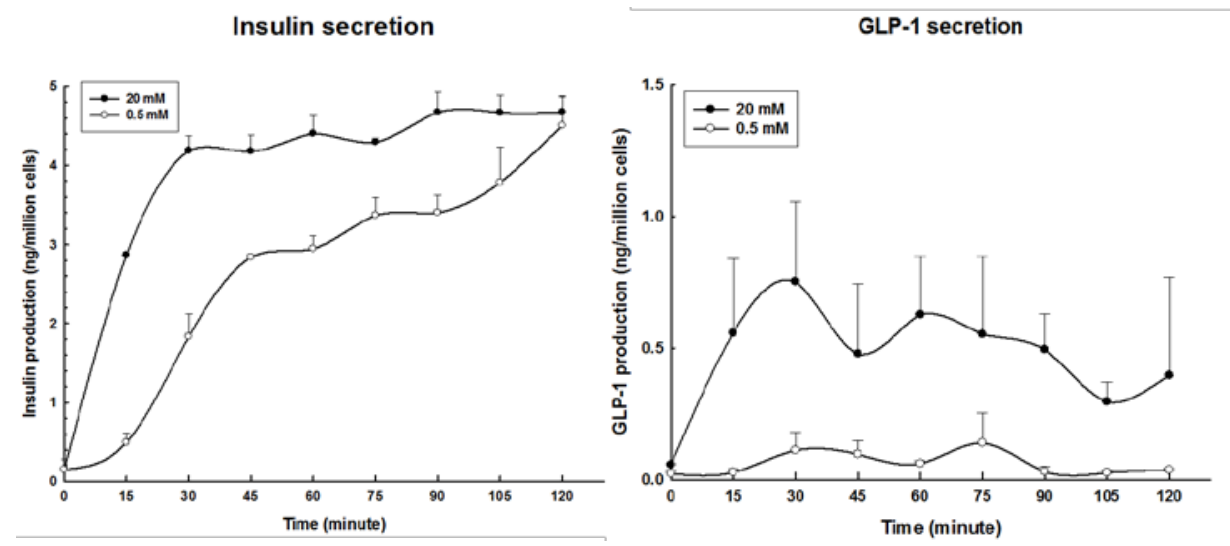

Figure 5. (A) Dynamic profile of insulin production during $2 \mathrm{~h}$ of perfusion at different glucose concentrations and $10 \mu \mathrm{l} / \mathrm{min} .20 \mathrm{mM}$ (black dots) and $0.5 \mathrm{mM}$ (white dots), $\mathrm{n}=3$. (B) Dynamic profile of GLP-1 production after $2 \mathrm{~h}$ of perfusion at different glucose concentrations: $20 \mathrm{mM}$ (black dots) and $0.5 \mathrm{mM}$ (white dots), $\mathrm{n}=3$.

It is known that GLP-1 secreted by L-cells affects the secretion of insulin from the $\beta$-cells ${ }^{11,12}$. By using the same microfluidic device as that used for the INS-1 cells, GLP-1 secretion from GLUTag cells at different glucose concentrations was measured. A higher glucose level resulted in more GLP-1 secretion (Fig. 5B). The noise in the measurement is due to the tiny amounts of GLP-1 measured $\left(<0.8 \mathrm{ng} / 10^{6}\right.$ cells $)$. After $30 \mathrm{~min}$, the amount of GLP-1 secreted at $20 \mathrm{mM}$ glucose concentration was 6.7 times higher than that at $0.5 \mathrm{mM}$ glucose concentration. However, the accumulative GLP-1 secretion at $20 \mathrm{mM}$ glucose concentration was 7.5 times higher than that at $0.5 \mathrm{mM}$ glucose concentration. This means that more GLP-1 was secreted at the onset of a higher glucose concentration in the medium after which the secretion level reached its maximum. However, at a lower glucose concentration, it took more time to reach that secretion level. The initial rise in the glucose concentration dictated the dynamics of the secretion of either the INS-1 or GLUTag cells.
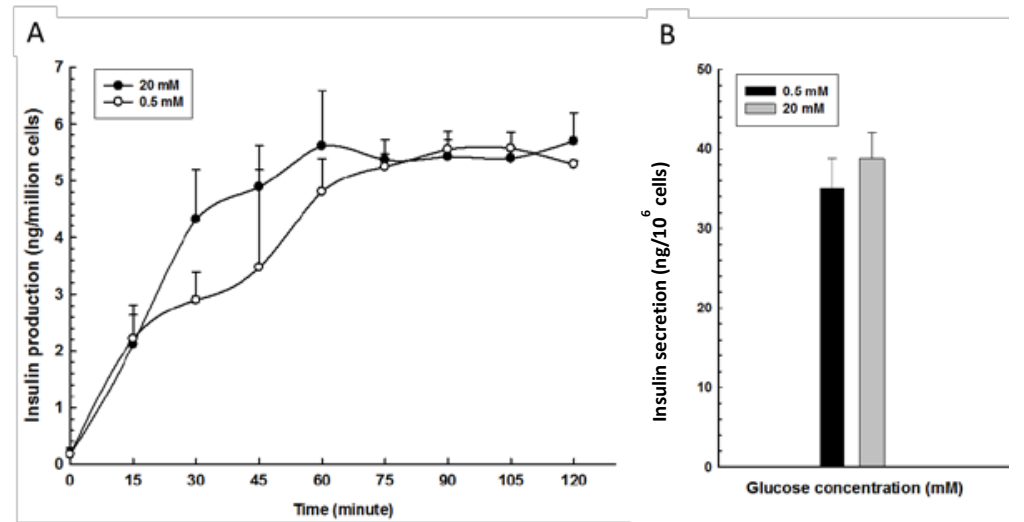

Figure 6. Effect of glucose concentration on insulin secretion in GLUTag-INS-1 on chip. Changes in insulin production depend on the glucose concentration. (A) shows insulin production during 2 h. $20 \mathrm{mM}$ glucose concentration (white dots) and $0.5 \mathrm{mM}$ glucose concentration (black dots), $\mathrm{n}=3$. (B) Accumulative insulin secretion after $2 \mathrm{~h}$. $0.5 \mathrm{mM}$ glucose concentration (black column) and $20 \mathrm{mM}$ glucose concentration (grey column); the column represents numerical means, $\mathrm{n}=3$ replications. Error bars represent standard deviation. 


\subsection{Effect of GLP-1 on insulin secretion in coupled microfluidic device}

To further enhance insulin secretion, the output of the GLUTag chip was coupled to the input of the INS-1 chip. Again, a dynamic effect was observed owing to the glucose concentration in the perfusion medium. Figure $6 \mathrm{~A}$ shows the insulin secretion by the INS-1 cells at glucose concentrations of 0.5 and $20 \mathrm{mM}$. Glucose affected the insulin secretion as well as the GLP-1 secretion by the GLUTag cells, which in turn affected the insulin secretion. Comparing these results with those shown in Fig. $5 \mathrm{~A}$, which shows the insulin production of only the glucose concentration, it can be observed that the insulin secretion reached the same level after $30 \mathrm{~min}$ as in the case of the co-culture chip. However, GLP-1 seems to boost insulin production after 30 min, owing to the secretion dynamics of GLP- 1 (Fig. 5B). After $60 \mathrm{~min}$, the co-culture reached the maximum secretion levels at $20 \mathrm{mM}$ glucose concentration, while at $0.5 \mathrm{mM}$ glucose concentration, this level was only reached after $90 \mathrm{~min}$.

As was the case with the single culture chip containing INS-1, higher glucose concentrations resulted in faster and higher insulin secretion. At $30 \mathrm{~min}$, the insulin production at $20 \mathrm{mM}$ glucose concentration was 1.5 times higher than that at $0.5 \mathrm{mM}$ glucose concentration; at $60 \mathrm{~min}$, the increase in insulin production was 1.2 times higher. Further, the accumulative insulin production after $2 \mathrm{~h}$ at $20 \mathrm{mM}$ glucose concentration was 1.1 times higher than that at $0.5 \mathrm{mM}$ glucose concentration (Fig. 6B).

Comparing the co-culture of INS-1 and GLUTag cells to the single-chip culture of only INS-1 cells, it can be observed that the insulin production in the co-culture at 0.5 and $20 \mathrm{mM}$ glucose concentrations was 1.5 and 1.1 times, respectively, compared to the single-culture chip. This clearly indicates that GLP-1 increased the insulin production and also that our endocrine system on a chip can mimic the in vivo endocrine interactions.

\section{Conclusions}

We have shown that microfluidics can give insights into the interaction between different cell types. Our results suggest that the 'endocrine system on a chip' can be used to observe dynamic changes in endocrine hormones (GLP-1 and insulin) in response to glucose stimuli. Moreover, we have shown that a co-culture of GLUTag cells producing GLP-1 stimulate insulin production in INS-1 cells and that dynamical changes are observed when comparing the co-culture chip with a single INS-1 chip. Furthermore, higher glucose concentration levels in the media result in faster and higher insulin secretion, up to a certain maximum secretion level. Reaching this maximum level does not depend on the glucose concentration but on the time the cells are exposed to a certain glucose concentration: a higher glucose concentration results in a shorter time to reach this level. The addition of GLP-1 in the co-culture chip boosts this maximum level, resulting in more insulin secretion from the INS-1 cells. 
As we can measure the dynamic profiles of insulin secretion by the $\beta$-cells, we believe that a microfluidics-based in vitro model can supplement in vivo models, because microfluidics allows for fast dynamic measurements of insulin production. It can also be used to effectively screen new drugs and test their effects on insulin production and $\beta$-cell restoration by observing changes in the model in real time.

\section{Acknowledgements}

We would like to thank Daniel J. Drucker from the Samuel Lunenfeld Research Institute, Mt. Sinai Hospital, and Seung-Hoi Koo from Korea University for providing the L-cells. This work was equally supported by the Technology Innovation Program (\#10050154, Business Model Development for Personalized Medicine Based on Integrated Genome and Clinical Information) funded by the Ministry of Trade, Industry \& Energy (MOTIE) and the grant (2016M3A9B4917320) through National Research Foundation (NRF) funded by the Ministry of Science, ICT and Future Planning (MSIP) in Korea.

\section{References}

1 D. Meetoo, P. McGovern and R. Safadi, Br. J. Nurs., 2007, 16, 1002-1007.

2 K. I. Rother, New Engl. J. Med., 2007, 356, 1499-1501.

3 Y. Okubo, A. Shimada, Y. Kanazawa, T. Shigihara, Y. Oikawa, T. Imai, J. Miyazaki and H. Itoh, Diabetes Res. Clin. Pract., 2008, 79, 18-23.

4 G. Kloppel, M. Lohr, K. Habich, M. Oberholzer and P. U. Heitz, Surv. Syn. Pathol. Res., 1985, 4, 110-125.

5 G. K. Gittes, Dev. Biol., 2009, 326, 4-35.

6 A. A. Elayat, M. M. Elnaggar and M. Tahir, J. Anat., 1995, 186, 629-637.

7 G. H. Patterson, S. M. Knobel, P. Arkhammar, O. Thastrup and D. W. Piston, Proc. Natl. Acad. Sci. USA, 2000, 97, 5203-5207.

8 M. J. Sheetz and G. L. King, JAMA, 2002, 288, 2579-2588.

9 R. A. Reimer, C. Darimont, S. Gremlich, V. Nicolas-Metral, U. T. Ruegg and K. Mace, Endocrinology, 2001, 142, 4522-4528.

10 G. Winkler, Orv. Hetil., 2013, 154, 248-255.

11 D. J. Drucker, Diabetes Care, 2003, 26, 2929-2940.

12 A. Mondragon, D. Davidsson, S. Kyriakoudi, A. Bertling, R. Gomes-Faria, P. Cohen, S. Rothery, P. Chabosseau, G. A. Rutter, G. da Silva Xavier, PLoS One, 2014, 9, e104873. doi: 10.1371/journal.pone.0104873. 
13 Y. C. Toh, C. Zhang, J. Zhang, Y. M. Khong, S. Chang, V. D. Samper, D. van Noort, D. W. Hutmacher and H. R. Yu, Lab Chip, 2007, 7, 302-309.

14 D. Huh, B. D. Matthews, A. Mammoto, M. Montoya-Zavala, H. Y. Hsin and D. E. Ingber, Science, 2010, 328, 1662-1668.

15 H. J. Kim, D. Huh, G. Hamilton and D. E. Ingber, Lab Chip, 2012, 12, 2165-2174.

16 P. M. Valencia, O. C. Farokhzad, R. Karnik and R. Langer, Nat. Nanotechnol., 2012, 7, 623629.

17 Y. C. Toh, T. C. Lim, D. Tai, G. Xiao, D. van Noort and H. Yu, Lab Chip, 2009, 9, 2026-2035.

18 D. Huh, H. Fujioka, Y. C. Tung, N. Futai, R. Paine, J. B. Grotberg and S. Takayama, Proc. Natl. Acad. Sci. USA, 2007, 104, 18886-18891.

19 W. F. Zheng, B. Jiang, D. Wang, W. Zhang, Z. Wang and X. Y. Jiang, Lab Chip, 2012, 12, 3441-3450.

20 D. van Noort, S. Park and N.-T. Nguyen, Micro and Nanosystems, 2014, 6, 215-231.

21 J. S. Mohammed, Y. Wang, T. A. Harvat, J. Oberholzer and D. T. Eddington, Lab Chip, 2009, 9, 97-106.

22 K. S. Sankar, B. J. Green, A. R. Crocker, J. E. Verity, S. M. Altamentova and J. V. Rocheleau, PLoS One, 2011, 6, e24904. doi: 10.1371/journal.pone.0024904.

23 D. Lee, Y. Wang, J. E. Mendoza-Elias, A. F. Adewola, T. A. Harvat, K. Kinzer, D. Gutierrez, M. R. G. Qi, D. T. Eddington and J. Oberholzer, Biomed. Microdevices, 2012, 14, 7-16.

24 J. G. Shackman, G. M. Dahlgren, J. L. Peters and R. T. Kennedy, Lab Chip, 2005, 5, 56-63.

25 J. F. Dishinger and R. T. Kennedy, Anal. Chem., 2007, 79, 947-954.

26 C. J. Easley, J. V. Rocheleau, W. S. Head and D. W. Piston, Anal. Chem., 2009, 81, 9086-9095.

27 W. J. Qian, C. A. Aspinwall, M. A. Battiste and R. T. Kennedy, Anal. Chem., 2000, 72, 711717.

28 R. N. Kulkarni, Int. J. Biochem. Cell Biol., 2004, 36, 365-371.

29 M. Asfari, D. Janjic, P. Meda, G. Li, P. A. Halban and C. B. Wollheim, Endocrinology, 1992, 130, 167-178.

30 L. Jansson and C. Hellerstrom, Diabetologia, 1983, 25, 45-50.

31 P. Ravassard, Y. Hazhouz, S. Pechberty, E. Bricout-Neveu, M. Armanet, P. Czernichow and R. Scharfmann, J. Clin. Invest., 2011, 121, 3589-3597.

32 D. J. Drucker, T. Jin, S. L. Asa, T. A. Young and P. L. Brubaker, Mol. Endocrinol., 1994, 8, 1646-1655.

33 E. L. LeCluyse, Eur. J. Pharm. Sci., 2001, 13, 343-368. 
34 L. M. Weber, K. N. Hayda and K. S. Anseth, Tissue Eng. Part A, 2008, 14, 1959-1968.

35 D. Meetoo, P. McGovern and R. Safadi, Br. J. Nurs., 2007, 16, 1002-1007.

36 K. I. Rother, New Engl. J. Med., 2007, 356, 1499-1501.

37 Y. Okubo, A. Shimada, Y. Kanazawa, T. Shigihara, Y. Oikawa, T. Imai, J. Miyazaki and H. Itoh, Diabetes Res. Clin. Pract., 2008, 79, 18-23.

38 G. Kloppel, M. Lohr, K. Habich, M. Oberholzer and P. U. Heitz, Surv. Syn. Pathol. Res., 1985, 4, 110-125.

39 G. K. Gittes, Dev. Biol., 2009, 326, 4-35.

40 A. A. Elayat, M. M. Elnaggar and M. Tahir, J. Anat., 1995, 186, 629-637.

41 G. H. Patterson, S. M. Knobel, P. Arkhammar, O. Thastrup and D. W. Piston, Proc. Natl. Acad. Sci. USA, 2000, 97, 5203-5207.

42 M. J. Sheetz and G. L. King, JAMA, 2002, 288, 2579-2588.

43 R. A. Reimer, C. Darimont, S. Gremlich, V. Nicolas-Metral, U. T. Ruegg and K. Mace, Endocrinology, 2001, 142, 4522-4528.

44 G. Winkler, Orv. Hetil., 2013, 154, 248-255.

45 D. J. Drucker, Diabetes Care, 2003, 26, 2929-2940.

46 A. Mondragon, D. Davidsson, S. Kyriakoudi, A. Bertling, R. Gomes-Faria, P. Cohen, S. Rothery, P. Chabosseau, G. A. Rutter, G. da Silva Xavier, PLoS One, 2014, 9, e104873. doi: 10.1371/journal.pone.0104873.

47 Y. C. Toh, C. Zhang, J. Zhang, Y. M. Khong, S. Chang, V. D. Samper, D. van Noort, D. W. Hutmacher and H. R. Yu, Lab Chip, 2007, 7, 302-309.

48 D. Huh, B. D. Matthews, A. Mammoto, M. Montoya-Zavala, H. Y. Hsin and D. E. Ingber, Science, 2010, 328, 1662-1668.

49 H. J. Kim, D. Huh, G. Hamilton and D. E. Ingber, Lab Chip, 2012, 12, 2165-2174.

50 P. M. Valencia, O. C. Farokhzad, R. Karnik and R. Langer, Nat. Nanotechnol., 2012, 7, 623 629.

51 Y. C. Toh, T. C. Lim, D. Tai, G. Xiao, D. van Noort and H. Yu, Lab Chip, 2009, 9, 2026-2035.

52 D. Huh, H. Fujioka, Y. C. Tung, N. Futai, R. Paine, J. B. Grotberg and S. Takayama, Proc. Natl. Acad. Sci. USA, 2007, 104, 18886-18891.

53 W. F. Zheng, B. Jiang, D. Wang, W. Zhang, Z. Wang and X. Y. Jiang, Lab Chip, 2012, 12, 3441-3450.

54 D. van Noort, S. Park and N.-T. Nguyen, Micro and Nanosystems, 2014, 6, 215-231. 
55 J. S. Mohammed, Y. Wang, T. A. Harvat, J. Oberholzer and D. T. Eddington, Lab Chip, 2009, 9, 97-106.

56 K. S. Sankar, B. J. Green, A. R. Crocker, J. E. Verity, S. M. Altamentova and J. V. Rocheleau, PLoS One, 2011, 6, e24904. doi: 10.1371/journal.pone.0024904.

57 D. Lee, Y. Wang, J. E. Mendoza-Elias, A. F. Adewola, T. A. Harvat, K. Kinzer, D. Gutierrez, M. R. G. Qi, D. T. Eddington and J. Oberholzer, Biomed. Microdevices, 2012, 14, 7-16.

58 J. G. Shackman, G. M. Dahlgren, J. L. Peters and R. T. Kennedy, Lab Chip, 2005, 5, 56-63.

59 J. F. Dishinger and R. T. Kennedy, Anal. Chem., 2007, 79, 947-954.

60 C. J. Easley, J. V. Rocheleau, W. S. Head and D. W. Piston, Anal. Chem., 2009, 81, 9086-9095.

61 W. J. Qian, C. A. Aspinwall, M. A. Battiste and R. T. Kennedy, Anal. Chem., 2000, 72, 711717.

62 R. N. Kulkarni, Int. J. Biochem. Cell Biol., 2004, 36, 365-371.

63 M. Asfari, D. Janjic, P. Meda, G. Li, P. A. Halban and C. B. Wollheim, Endocrinology, 1992, 130, $167-178$.

64 L. Jansson and C. Hellerstrom, Diabetologia, 1983, 25, 45-50.

65 P. Ravassard, Y. Hazhouz, S. Pechberty, E. Bricout-Neveu, M. Armanet, P. Czernichow and R. Scharfmann, J. Clin. Invest., 2011, 121, 3589-3597.

66 D. J. Drucker, T. Jin, S. L. Asa, T. A. Young and P. L. Brubaker, Mol. Endocrinol., 1994, 8, 1646-1655.

67 E. L. LeCluyse, Eur. J. Pharm. Sci., 2001, 13, 343-368.

68 L. M. Weber, K. N. Hayda and K. S. Anseth, Tissue Eng. Part A, 2008, 14, 1959-1968. 